\title{
A Review of Potential Mechanisms of Cryptogenic Stroke and a Recommended Approach to Diagnosis
}

\author{
Catherine E Arnold \\ Department of Neurology, Lenox Hill Hospital, New York, NY, USA
}

DOI: https://doi.org/10.17925/USN.2021.17.2.104

\begin{abstract}
$\mathrm{C}$ ryptogenic strokes have no probable cause despite appropriate initial testing, and are common, representing at least 20-30\% of all ischaemic strokes. Cryptogenic strokes occur more frequently in younger individuals and those without traditional stroke risk factors. Multiple potential mechanisms have been proposed and include cardioembolic source, proximal arterial source, venous source (in the presence of a right-to-left shunt), and more rare causes, such as genetic syndromes associated with stroke. Determining the mechanism is important, as cryptogenic strokes are associated with increased risk of recurrent stroke compared with strokes due to a known mechanism. Defining a stroke mechanism allows for the best treatment for secondary stroke prevention. This article reviews the standard initial evaluation recommended for almost all patients with ischaemic stroke, many potential causes of cryptogenic stroke and recommended additional evaluations to better identify stroke mechanism for patients with cryptogenic stroke.
\end{abstract}

\section{Keywords}

Stroke, ischaemic stroke, cryptogenic stroke, embolic stroke of undetermined source, embolic stroke of undetermined source (ESUS)

Disclosures: Catherine E Arnold has no financial or non-financial relationships or activities to declare in relation to this article.

Review process: Double-blind peer review.

Compliance with ethics: This study involves a review of the literature and did not involve any studies with human or animal subjects performed by the author.

Data availability: Data sharing is not applicable to this article as no datasets were generated or analysed during the writing of this article.

Authorship: The named author meets the International Committee of Medical Journal Editors (ICMJE) criteria for authorship of this manuscript, takes responsibility for the integrity of the work as a whole, and has given final approval for the version to be published.

Access: This article is freely accessible at touchNEUROLOGY.com. (c) Touch Medical Media 2021

Received: 8 October 2021

Accepted: 22 November 2021

Published online: 21 December 2021

Citation: touchREVIEWS in Neurology. 2021;17(2): 104-9

Corresponding author: Catherine E Arnold, Department of Neurology, Black Hall, 8th Floor, Lenox Hill Hospital, 130 E 77th Street, New York, NY 10075, USA. E: carnold1@northwell.edu

Support: No funding was received in the publication of this article.
Ischaemic stroke may occur due to several potential mechanisms. Mechanisms are classically described as large artery atherosclerosis, small-vessel occlusion, cardioembolism, stroke of other determined aetiology (i.e. vasculitis, genetic disorder, etc.) and stroke of undetermined aetiology. Historically, the definition of stroke of undetermined aetiology has included strokes with multiple potential mechanisms, as well as those with negative or incomplete evaluations. ${ }^{1}$ Over time, as the approach to stroke evaluation has evolved, the term cryptogenic stroke has largely been reserved for strokes with no identified cause, despite adequate standard evaluation. ${ }^{1-3}$ Since most cryptogenic strokes are thought to be embolic, the term embolic stroke of undetermined source (ESUS) has also become popular, and is often used synonymously with cryptogenic stroke. ESUS, specifically, is defined as a stroke not attributed to a lacunar mechanism (i.e. $>2.0 \mathrm{~cm}$ ), not associated with $\geq 50 \%$ intracranial or extracranial arterial stenosis, and not due to a major source of cardioembolism, such as atrial fibrillation. ${ }^{1-4}$

An estimated $20-30 \%$ of all strokes will have no probable cause despite appropriate initial testing, which equates to $150,000-240,000$ cryptogenic strokes per year in the United States. ${ }^{2.3}$ Typically, patients with cryptogenic stroke are younger and have fewer traditional vascular risk factors., ${ }^{, 5}$ Numerous mechanisms have been proposed for cryptogenic stroke, including cardioembolism from occult atrial fibrillation, cardiac structural abnormalities, paroxysmal embolism, hypercoagulable or prothrombotic states, sub-stenotic large-vessel disease, aortic atherosclerotic disease and other non-atherosclerotic vasculopathies. ${ }^{6}$ Determining the underlying mechanism is important, since cryptogenic strokes are associated with increased risk of recurrent stroke compared with strokes due to a defined mechanism. Knowing the source of stroke allows for the best treatment to prevent secondary strokes. ${ }^{5.7}$ Herein, we discuss the standard evaluation of ischaemic stroke, potential causes of cryptogenic stroke and recommended additional evaluations to better identify stroke mechanism.

\section{Initial evaluation of ischaemic stroke}

Though the approach to stroke workup should be individualized and adjusted to the age, gender and specific risk factors of each patient, certain studies should almost always be performed. In general, the initial goal of testing is to assess for one of the three common mechanisms of stroke: large-vessel arteriosclerotic disease, small-vessel disease and cardioembolism.' Initial evaluations should include brain and vessel imaging, echocardiogram, cardiac monitoring and basic blood tests. ${ }^{6}$ Though computed tomography (CT) of the head is an option and often the first study performed during assessment in the acute setting of suspected stroke, magnetic resonance imaging (MRI) of the brain is often far superior in detecting abnormalities and is often warranted. An MRI will better evaluate the stroke topography, which often can provide clues into potential mechanism. For example, multiple acute strokes within different vascular territories are worrisome for proximal or cardioembolic source, whereas a small stroke within the deep structures of the brain, which is 
Figure 1: A suggested approach for evaluating patients presenting with ischaemic stroke

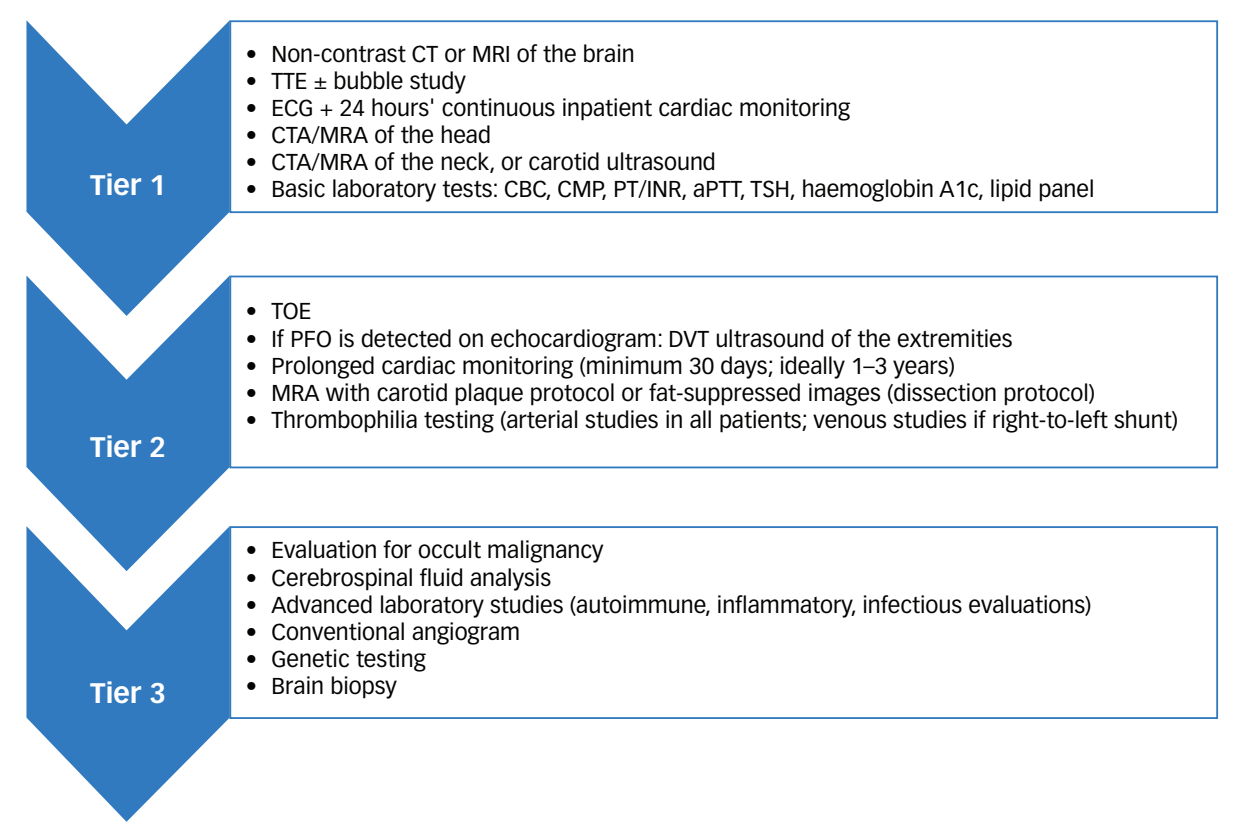

Tier 1 testing represents the recommended standard evaluation for almost all patients with stroke. Tier 2 testing should be considered in patients with cryptogenic stroke following unrevealing Tier 1 testing. Tier 3 testing evaluates for rare causes of stroke and should be tailored to each patient's clinical presentation and risk factors. aPPT = activated partial thromboplastin time; $C B C=$ complete blood count; $C M P=$ comprehensive metabolic panel: $C T A=$ computed tomography angiography; $C T=$ computed tomography; $D V T=$ deep vein thrombosis; $E C G$ = electrocardiogram; $M R A=$ magnetic resonance angiography; $M R I=$ magnetic resonance imaging; $P F O=$ patent foramen ovale; $P T / I N R=$ prothrombin time/international normalized ratio; TOE = transoesophageal echocardiogram; TSH = thyroid stimulating hormone; TTE = transthoracic echocardiogram.

also associated with a significant burden of white matter disease, is more consistent with a lacunar infarct due to small-vessel pathology. Carotid ultrasound (US), CT angiography (CTA) or MR angiography (MRA) of the neck are helpful in evaluating for large-vessel atherosclerotic disease within the neck. CTA or MRA of the head is also highly recommended given the potential for intracranial disease as a mechanism of stroke that would not be readily appreciated on neck vessel imaging. ${ }^{1-7}$

At a minimum, an electrocardiogram (ECG) and inpatient cardiac monitoring should be performed on all patients admitted with stroke/transient ischaemic attack (TIA). In those without clear smallvessel mechanism, an additional 24 hours of cardiac monitoring is recommended to evaluate for atrial fibrillation. Typically, a transthoracic echocardiogram (TTE) or transoesophageal echocardiogram (TOE) is recommended to identify potential structural cardiac sources of stroke, such as intracardiac thrombus or valvular disease. Basic laboratory tests should be performed to identify underlying coagulopathy and to assess for common modifiable risk factors of stroke (i.e. diabetes, hyperlipidaemia and thyroid disease). If these initial studies do not reveal stroke mechanism, the stroke is assumed cryptogenic and further evaluations are warranted (Figure 1).

\section{Potential causes of cryptogenic stroke}

\section{Occult atrial fibrillation}

Occult atrial fibrillation is the likely cause of up to $30 \%$ of cryptogenic strokes. It is typically asymptomatic and paroxysmal, making detection difficult. However, detecting the arrythmia is important as its treatment, anticoagulation, ultimately improves secondary stroke prevention. ${ }^{8.9}$

The standard stroke evaluation typically includes 24-hour cardiac monitoring, but the sensitivity of capturing atrial fibrillation during this period is low. ${ }^{10}$ Thus, patients with cryptogenic stroke warrant more prolonged monitoring. Multiple devices are available with variable durations of cardiac monitoring as options. Not surprisingly, longer periods of continuous monitoring are consistently associated with higher rates of detection of atrial fibrillation, and implantable cardiac monitors have the highest rate of detection of all devices., ${ }^{8,11-13}$ In fact, $40 \%$ of patients with cryptogenic stroke with implantable cardiac monitors were found to have atrial fibrillation, with a mean time to detection of 8 months. ${ }^{14}$ Older patients ( $>75$ years old), patients with ejection fraction (EF) $<40 \%$, and those with prolonged PR interval on initial ECG have higher rates of detection. ${ }^{9,10}$

TTES and, especially, TOEs can also provide clues of the risk of underlying atrial fibrillation. Enlargement of the left atrium and reduced left atrial emptying velocities are findings of particular concern. Even more concerning are findings of thrombus, 'smoke' and 'spontaneous echo contrast' within the left atrium and/or left atrial appendage. Patients with such findings are at particularly high risk of stroke due to atrial fibrillation, and anticoagulation should be seriously considered for secondary stroke prevention. ${ }^{10-12}$

\section{Patent foramen ovale}

Patent foramen ovale (PFO) is a relatively frequent inter-atrial communication found in approximately $25-30 \%$ of the general population, and is often clinically insignificant. ${ }^{13-15}$ However, a higher frequency of PFO is found in patients with cryptogenic stroke, raising the question of its potential role in stroke pathogenesis. ${ }^{13}$ Potential mechanisms of stroke in patients with a PFO include paroxysmal embolism from a venous source or embolization of thrombotic material formed on the PFO, or associated atrial septal aneurysm (redundant and mobile inter-atrial septal tissue)..$^{14}$

TTE and TOE with saline contrast injection are often used to detect PFOS. TOE is considered the gold standard for detection with sensitivity of approximately $90 \%$ and specificity of $95 \% .6,15,16$ However, older patients or patients with severe dysphagia may be less able to tolerate the 
procedure. Further, sedation used during the procedure may limit the effectiveness of Valsalva manoeuvres, which aid in diagnosis. A TTE with bubble study is an alternative, less invasive means of detecting PFOs, though the sensitivity and specificity are lower than TOE. ${ }^{13}$ Transcranial Doppler ultrasonography with bubble contrast material can also be used

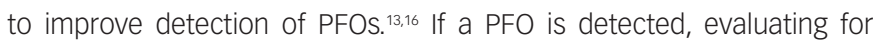
thrombophilia and deep venous thrombus (DVT) of the extremities may be warranted to assess for a potential source of paroxysmal emboli. ${ }^{6}$

Importantly, detecting a PFO in a patient with a cryptogenic stroke does not necessarily prove a causal relationship, given the frequency of the finding in the general population. Previous work has demonstrated that among patients with cryptogenic stroke who had a PFO, the PFO was probably the cause of stroke in less than $50 \% .{ }^{16}$ PFOs in younger patients ( $\leq 60$ years old), those with right-to-left shunting through the defect, and those with an associated atrial septal aneurysm are higher risk and are more likely to be the cause of stroke. ${ }^{14,15}$ PFOs in patients with known venous thrombus or in patients with a pure venous hypercoagulable state are more likely to have a causal relationship with stroke as well. ${ }^{16}$ In general, investigations to exclude alternative causes of stroke, particularly occult atrial fibrillation and underlying hypercoagulable states, are recommended prior to attributing cryptogenic stroke to the PFO.

Much debate has surrounded the treatment of PFOs in cryptogenic stroke over the last several years. Until relatively recently, antithrombotic therapy (typically with antiplatelet) was recommended over PFO closure after several studies showed no significant benefit of PFO closure over medical therapy alone. ${ }^{17,18}$ However, subsequent studies have shown benefit in stroke reduction with PFO closure in combination with antiplatelet in patients $\leq 60$ years old and those with PFOs with high-risk features (i.e. intra-atrial shunt and atrial septal aneurysm). ${ }^{19}$ More recent data show persistent benefit of PFO closure despite age $>60$, suggesting that the high-risk features of the PFO should be considered over age when determining causal relationship of cryptogenic stroke and when optimizing treatment. ${ }^{20}$

As an aside, intrapulmonary shunts (i.e. pulmonary arteriovenous malformations or fistulas) are another cause of right-to-left shunting that may potentially cause ischaemic stroke and are typically detected by TTE or TOE during stroke evaluation..$^{21,22} \mathrm{~A}$ few studies have shown a higher prevalence of these shunts in patients with cryptogenic strokes or TIAS. ${ }^{21,22}$ However, further work is needed in this area to better determine the clinical significance and association between intrapulmonary shunts and stroke.22

\section{Aortic embolism}

Aortic arch plaque is an important possible source of cryptogenic stroke. The risk of embolic events is highest with complex plaque. Complex plaque is defined as atherosclerotic plaque of $\geq 4 \mathrm{~mm}$ thickness and associated with ulcerations, mobile debris or superimposed thrombi. ${ }^{23}$ Aortic atherosclerosis is best assessed on TOE, but can also be seen on epi-aortic US and CT or MRI with or without angiography. ${ }^{24}$ In patients with ESUS undergoing TOE, 30\% had aortic arch atherosclerosis and $8 \%$ had high-risk complex plaque. ${ }^{23}$ Proximal complex plaque was considered highest risk given its proximity to the main neck vessels. ${ }^{24}$ However, recent data suggesting that plaque is more distal in the descending aorta may also be suspicious as, during diastole, there is significant retrograde flow such that thrombi may reach the vessels of the neck and ultimately result in stroke. ${ }^{25,26}$ This is of particular interest because complex plaque is more frequently located in the distal aorta compared
Table 1: Recommended evaluation for thrombophilia in cryptogenic stroke

\begin{tabular}{|c|c|}
\hline $\begin{array}{l}\text { Thrombophilia associated with } \\
\text { arterial and venous thrombi* }\end{array}$ & $\begin{array}{l}\text { Thrombophilia associated with } \\
\text { venous thrombi }{ }^{+}\end{array}$ \\
\hline $\begin{array}{l}\text { Anti- } \beta \text { - } 2 \text { glycoprotein antibodies } \\
\text { (IgG, IgM) } \\
\text { Anticardiolipin antibodies (IgG, IgM) } \\
\text { Lupus anticoagulant }\end{array}$ & $\begin{array}{l}\text { Factor V Leiden } \\
\text { Prothrombin mutation } \\
\text { Protein C } \\
\text { Protein S } \\
\text { Antithrombin } \\
\text { Methylenetetrahydrofolate reductase } \\
\text { (MTHFR) } \\
\text { Homocysteine }\end{array}$ \\
\hline
\end{tabular}

Thrombophilia testing should be considered in young patients with cryptogenic stroke, particularly in those with personal or family history of thromboembolism (i.e. unprovoked deep vein thrombosis, pulmonary embolism, recurrent miscarriages, etc.) or in those with known family history of thrombophilia.

*Tests recommended in all patients undergoing thrombophilia testing; ${ }^{*}$ Tests recommended only in patients with right-to-left shunt (i.e. PFO)

$I g=$ immunoglobulin; $P F O=$ patent foramen ovale.

with the proximal aorta. ${ }^{27}$ In addition, it has been speculated that aortic atherosclerosis is more likely to cause strokes in the left hemisphere, as most atherosclerotic plaque is located distally to the innominate artery, which supplies circulation to the right-sided vasculature. ${ }^{27}$ However, this finding has not been consistent. ${ }^{23}$

The optimal treatment of aortic atherosclerotic disease in cryptogenic stroke is unclear. However, the current preference is a combination of antiplatelet medications and high-intensity statin therapy. Studies comparing anticoagulation with antiplatelet therapy have been inconclusive, and more research is needed in this area to define the best treatment. ${ }^{23,24,28}$

\section{Sub-stenotic carotid disease}

Traditionally, ischaemic strokes or TIAs were only attributed to carotid disease when the stenosis was greater than $50 \% .{ }^{1}$ However, more recent data suggest that even carotid disease $\leq 50 \%$ can be pathologic and that the composition of the plaque determines its vulnerability and risk of causing TIA or stroke. ${ }^{29-31}$ Recent advancements in imaging have allowed for better characterization of plaque composition. Intraplaque haemorrhage, lipid-rich necrotic core and thinning or rupture of the fibrous cap of the atherosclerotic plaque are all associated with increased risk of embolic events. ${ }^{29-32}$ MRA with plaque composition protocol is the gold-standard technique, allowing for the most detailed assessment of plaque composition. However, CTA, positron emission tomography (PET) CT and ultrasonography with contrast enhancement can all be used to assess plaque morphology and characteristics, with varying sensitivity and specificity in detecting high-risk features. ${ }^{33}$

Despite this advancement, limitations still exist in the optimal treatment of non-stenotic carotid disease. The hope is that, with research, we will better know how to use this information to guide patient-specific treatment, i.e. medical therapy versus carotid intervention and, if intervention is warranted, which intervention is most appropriate. Further research is needed in this area. ${ }^{30,33,34}$

\section{Carotid web}

Though literature recognizing the entity is relatively sparce, carotid webs have been recently identified as an under-recognized cause of stroke in young patients without traditional stroke risk factors. ${ }^{35,36} \mathrm{~A}$ carotid web 
Table 2: Genetic syndromes associated with stroke

\begin{tabular}{|c|c|c|c|c|}
\hline Condition & Clinical features & Cause & Testing & Treatment \\
\hline Fabry disease & $\begin{array}{l}\text { TIA, strokes in the young } \\
\text { MRI/MRA: white matter disease, often with } \\
\text { vertebrobasilar circulation involvement, } \\
\text { dolichoectasia of vessels } \\
\text { Other features: } \\
\text { Small fibre peripheral neuropathy (painful) } \\
\text { Tinnitus } \\
\text { Angiokeratomas or telangiectasias } \\
\text { Gastrointestinal, renal, cardiac involvement }\end{array}$ & $\begin{array}{l}\text { X-linked disorder } \\
\text { Deficient activity in } \\
\text { Iysosomal hydrolase } \alpha \text {-GLA }\end{array}$ & $\begin{array}{l}\text { Leukocyte GLA activity } \\
\text { Molecular genetic testing }\end{array}$ & Recombinant $\alpha$-GLA \\
\hline CADASIL & $\begin{array}{l}\text { Subcortical stroke in the young (median age } 50-55 \text { ) } \\
\text { MRI: significant T2 hyperintensities, often involving } \\
\text { white matter of temporal poles; brain atrophy; } \\
\text { micro-haemorrhages } \\
\text { Other features: } \\
\text { Cognitive impairment } \\
\text { Migraines }\end{array}$ & $\begin{array}{l}\text { Autosomal dominant } \\
\text { NOTCH3 gene mutation on } \\
\text { chromosome } 19\end{array}$ & $\begin{array}{l}\text { Skin biopsy } \\
\text { Genetic testing }\end{array}$ & $\begin{array}{l}\text { Aggressive management of } \\
\text { cerebrovascular risk factors } \\
\text { Antiplatelet } \\
\text { Migraine prophylactic } \\
\text { medications }\end{array}$ \\
\hline CARASIL & $\begin{array}{l}\text { Subcortical stroke in the young } \\
\text { Other features: } \\
\text { Early alopecia } \\
\text { Early cervical/lumbar spondylosis }\end{array}$ & $\begin{array}{l}\text { Autosomal recessive } \\
\text { HTRA1 gene on chromosome } \\
10\end{array}$ & Genetic testing & $\begin{array}{l}\text { Aggressive management of } \\
\text { cerebrovascular risk factors } \\
\text { Antiplatelet }\end{array}$ \\
\hline MELAS & $\begin{array}{l}\text { Stroke with variable vascular distributions in young } \\
\text { patients (often }<40 \text { years old) } \\
\text { Other features: } \\
\text { Seizures } \\
\text { Migraine-like headaches } \\
\text { Lactic acidosis } \\
\text { Dementia } \\
\text { Muscle weakness } \\
\text { Short status } \\
\text { Hearing loss }\end{array}$ & $\begin{array}{l}\text { Mitochondrial disorder } \\
80 \% \text { associated with A3243G } \\
\text { mutation in a gene encoding } \\
\text { transfer RNA }\end{array}$ & $\begin{array}{l}\text { Muscle biopsy } \\
\text { Genetic testing }\end{array}$ & $\begin{array}{l}\text { Therapies to reduce } \\
\text { oxidative stress (Coenzyme } \\
\text { Q10), levo-carnitine, } \\
\text { B vitamins } \\
\text { Avoid valproate, statins }\end{array}$ \\
\hline Sickle cell disease & $\begin{array}{l}\text { Cause of both ischaemic and haemorrhagic stroke in } \\
\text { the young } \\
\text { Can be associated with non-atherosclerotic cerebral } \\
\text { vasculopathy (Moyamoya-like vasculopathy) } \\
\text { Most prevalent in African or African American decent }\end{array}$ & $\begin{array}{l}\text { Autosomal recessive } \\
\text { Point mutation of } \\
\text { 『-polypeptide chain of } \\
\text { haemoglobin }\end{array}$ & $\begin{array}{l}\text { Usually detected in } \\
\text { prenatal or newborn } \\
\text { testing } \\
\text { Multiple laboratory tests } \\
\text { available for adults }\end{array}$ & $\begin{array}{l}\text { Hydroxyurea } \\
\text { If TCD velocities of MCA } \\
>200 \mathrm{~cm} / \mathrm{s} \text {, exchange } \\
\text { transfusion therapy is } \\
\text { recommended in children }\end{array}$ \\
\hline
\end{tabular}

Examples of several genetic syndromes associated with stroke and the clinical features, genetic defect, testing and treatment associated with each disorder.51,52

CADASIL = cerebral autosomal dominant arteriopathy with subcortical infarcts and leukoencephalopathy: CARASIL = cerebral autosomal recessive arteriopathy with subcortical infarcts and leukoencephalopathy; GLA = galactosidase $A ;$ HRTA1 = high-temperature requirement $A$ serine peptidase 1; MCA = middle cerebral artery; $M E L A S=$ mitochondrial encephalopathy, lactic acidosis and stroke-like episodes; MRA = magnetic resonance angiography; MRI = magnetic resonance imaging; NOTCH3 = neurogenic locus notch homologue 3; RNA = ribonucleic acid; TCD = transcranial Doppler; TIA = transient ischaemic attack.

is defined radiographically as a posterolateral intraluminal filling defect of the proximal internal carotid artery, often described as a 'shelf' of tissue projecting into the lumen. ${ }^{35-37}$ Carotid webs can be appreciated with carotid US, though are often better seen on CTA or MRA, with the gold standard for detection being conventional angiogram. ${ }^{35,36}$ The composition of surgically resected carotid webs is consistent with fibrous proliferation, and thus carotid webs represent a form of focal atypical fibromuscular dysplasia rather than a variant of atherosclerotic disease. ${ }^{37}$ Most carotid webs are associated with only mild carotid stenosis. They may result in stroke due to blood stasis, thrombus formation and secondary embolization. ${ }^{37-40}$
Bilateral disease is not uncommon; almost $60 \%$ of patients with symptomatic disease will have asymptomatic contralateral disease as well. ${ }^{38,39}$ Symptomatic disease is seen most commonly in young women with a median age of 46 and of African American race. ${ }^{37,40}$

Despite an elevated rate of stroke recurrence with carotid webs, ${ }^{38,39}$ secondary stroke prevention is not well defined. Patients are often managed conservatively with antiplatelet therapy, but over half of patients have stroke recurrence within 1 year after the first event/stroke. Patients treated with anticoagulation have an even higher rate of recurrent stroke than those on antiplatelet therapy. ${ }^{37,40}$ Thus, carotid revascularization 
Table 3: Other causes of non-atherosclerotic vasculopathy ${ }^{2,3,5,7}$

\begin{tabular}{|c|c|c|}
\hline Condition & Clinical features & Evaluation \\
\hline Arterial dissection & $\begin{array}{l}\text { Ipsilateral headache/neck pain } \\
\text { History of minor or major head/neck trauma } \\
\text { History or clinical features suggestive of underlying connective } \\
\text { tissue disorder (i.e. hyperextensible joints, double-jointedness, skin } \\
\text { hyperextension, pectus excavatum, etc.) } \\
\text { Horner syndrome }\end{array}$ & $\begin{array}{l}\text { CTA } \\
\text { MRA with fat-suppressed images } \\
\text { Angiogram if above is negative and clinical suspicion remains } \\
\text { high }\end{array}$ \\
\hline $\begin{array}{l}\text { Reversible cerebral } \\
\text { vasoconstriction syndrome }\end{array}$ & $\begin{array}{l}\text { Recurrent }(\geq 3) \text { thunderclap headaches with/without neurologic deficits } \\
\text { Triggers: physical exertion, stress, Valsalva manoeuvres, use of } \\
\text { medications/substances associated with reversible cerebral } \\
\text { vasoconstriction syndrome (triptans, SSRIs, energy-enhancing agents, } \\
\text { cocaine, marijuana, etc.) } \\
\text { Imaging may show watershed ischaemic strokes } \pm \text { cortical } \\
\text { subarachnoid haemorrhage } \\
\text { Vessel imaging may be falsely negative early in the course of disease }\end{array}$ & $\begin{array}{l}\text { CTA } \\
\text { MRA } \\
\text { Conventional angiogram } \\
\text { Cerebrospinal fluid analysis to rule out subarachnoid } \\
\text { haemorrhage if first thunderclap headache }\end{array}$ \\
\hline Vasculitis & $\begin{array}{l}\text { Recurrent strokes in varying vascular distributions } \\
\text { Headaches } \\
\text { Encephalopathy } \\
\text { Focal neurologic deficits, often with progressive relapsing course } \\
\text { Possible history of autoimmune/rheumatologic disease or infection }\end{array}$ & $\begin{array}{l}\text { CTA } \\
\text { MRA } \\
\text { Conventional angiogram } \\
\text { Cerebrospinal fluid analysis } \\
\text { Laboratory studies to evaluate for potential autoimmune, } \\
\text { inflammatory or infectious causes }\end{array}$ \\
\hline
\end{tabular}

Examples of non-atherosclerotic vasculopathy with associated clinical features and recommended initial evaluations.

CTA = computed tomography angiography; MRA = magnetic resonance angiography; SSRI = selective serotonin reuptake inhibitor

with either carotid endarterectomy or stenting has been proposed as an alternative treatment option with a much lower risk of stroke recurrence. Further work comparing long-term outcomes among different treatment options is needed to determine best management of this condition. ${ }^{36-38,41}$

\section{Hypercoagulable state due to thrombophilia}

The evaluation of cryptogenic stroke often includes testing for underlying thrombophilia (Table 1). Both inherited and acquired thrombophilia are associated with stroke, particularly in young patients and in those with prior personal or family history of thrombotic events. ${ }^{6}$

Inherited thrombophilia typically causes venous thromboembolism and may be implicated in cryptogenic stroke in the presence of cardiac and possibly pulmonary right-to-left shunts. Inherited thrombophilia includes deficiencies in protein $\mathrm{C}$, protein $\mathrm{S}$ and antithrombin. ${ }^{22}$ Caution when interpreting abnormal results is warranted, as levels can be affected by illness, anticoagulant use and acute thrombosis. Often, repeat testing is needed to confirm. Genetic mutations such as factor V Leiden mutation, prothrombin G20210A gene mutation and elevated levels of factor VIII are also associated with stroke. ${ }^{43}$ Homozygosity or compound heterozygosity of factor V Leiden and prothrombin G20210A gene mutations lead to a considerably higher risk of thrombosis compared with heterozygosity for factor $\mathrm{V}$ Leiden mutation alone. ${ }^{22,43}$

Antiphospholipid syndrome (APLS) represents a relatively common cause of acquired thrombophilia that can result in both venous and arterial thrombosis, possibly causing cryptogenic stroke. Diagnosis of APLS requires a thromboembolic event and the presence of specific antiphospholipid antibodies (lupus anticoagulant, anti- $\beta-2$ glycoprotein-1 antibodies and/or anticardiolipin antibodies). Results of testing may be unreliable in the setting of certain illnesses or inflammatory states, recent thrombosis or anticoagulation. Thus, repeat testing 12 weeks following the initial testing is recommended to confirm the diagnosis. ${ }^{42,44}$

If stroke is attributed to an underlying thrombophilia, long-term anticoagulation therapy is generally recommended for secondary stroke prevention. Consultation with haematology is recommended. ${ }^{43}$

\section{Malignancy}

Malignancy is associated with a pro-inflammatory and hypercoagulable state and can result in ischaemic stroke through various mechanisms. ${ }^{45,46}$ Though uncommon, ischaemic stroke can be the first presentation of cancer. Overall, the incidence of cancer detected after ischaemic stroke is low but is higher in cases of cryptogenic stroke. Though testing for malignancy is not necessary for all patients with cryptogenic stroke, certain historical or clinical features, such as older age, smoking history, the presence of constitutional symptoms and elevated inflammatory or pro-thrombotic makers, should raise concern and prompt further evaluation. ${ }^{47}$

In general, outcomes are typically worse for patients with cancer who have a stroke. This may be, in part, due to debility related to the initial stroke and recurrent strokes. ${ }^{47,48}$ Alongside treating the underlying malignancy, anticoagulation with low-molecular-weight heparin has been best studied and is recommended as first-line therapy for secondary stroke prevention in cancer-related stroke. Warfarin has also been used with favourable results. The more convenient direct oral anticoagulants, such as apixaban, are becoming more frequently used but with mixed results..$^{46,99,50}$ 


\section{Genetic syndromes associated with stroke}

Inherited stroke syndromes should be considered in young patients with a family history of stroke in the young, and in those with recognizable clinical phenotypes of specific genetic syndromes (Table 2). When clinical suspicion is high for an individual syndrome, genetic testing should be considered, as an accurate diagnosis may have therapeutic implications and allow for familial genetic counselling. ${ }^{51,52}$

\section{Non-atherosclerotic vasculopathy}

Other, non-atherosclerotic vasculopathies, such as arterial dissection, reversible cerebral vasoconstriction syndromes and vasculitis are among potential causes for cryptogenic stroke. Typically, patients will present with features that raise suspicion for a specific condition, and diagnostic evaluation and treatment should be tailored to the individual (Table 3) ${ }^{2.3,5,7}$

\section{Summary and conclusions}

Cryptogenic stroke is common and most often occurs in younger patients with fewer traditional risk factors for stroke. ${ }^{4-5}$ Given the higher risk of recurrent stroke, a thorough evaluation for potential mechanisms is warranted. ${ }^{5,7}$ All patients should undergo a standard comprehensive evaluation to assess for the most common mechanisms of stroke. Additional studies beyond the initial evaluation should be tailored to the patient's clinical history and risk factors as much as possible; evaluations for cryptogenic stroke are often costly if not covered by insurance, are potentially unavailable in less resource-rich locations and are of relatively low yield. The best treatment for secondary stroke prevention is dependent on the mechanism of stroke, and risk-factor modification and antiplatelet therapy are often recommended in the absence of definitive cause. ${ }^{1,49-50}$
1. Adams HP, Bendixen BH, Kappelle $L$, et al. Classification of subtype of acute ischemic stroke. Definitions for use in a multicenter clinical trial. Toast. Trial of org 10172 in acute strok multicenter clinical trial. Toast. Tria

2. Fonseca AC, Ferro JM. Cryptogenic stroke. Eur J Neurol. 2015;22:618-23

3. Saver JL. Cryptogenic stroke. N Eng/ J Med. 2016;375:e26

4. Li L, Yiin GS, Geraghty OC, et al. Incidence, outcome, risk factors, and long-term prognosis of cryptogenic transient ischaemic attack and ischaemic stroke: A population-based study. Lancet Neurol. 2015;14:903-13.

5. Hart RG, Catanese L, Perera KS, et al. Embolic stroke of undetermined source: A systematic review and clinical update. Stroke. 2017;48:867-72.

6. Saver JL. Clinical practice. Cryptogenic stroke. N Eng/ J Med. 2016:374:2065-74.

7. Bang OY, Lee PH, Joo SY, et al. Frequency and mechanisms of stroke recurrence after cryptogenic stroke. Ann Neurol. 2003:54:227-34

8. Brachmann J, Morillo CA, Sanna T, et al. Uncovering atrial fibrillation beyond short-term monitoring in cryptogenic stroke patients: Three-year results from the cryptogenic stroke and underlying atrial fibrillation trial. Circ Arrhythm Electrophysiol. 2016;9:0003333

9. Glotzer TV, Ziegler PD. Cryptogenic stroke: Is silent atria fibrillation the culprit? Heart Rhythm. 2015;12:234-41.

10. Dinh T, Baur LH, Pisters R, et al. Feasibility of tee-guided stroke risk assessment in atrial fibrillation-background, aims, design and baseline data of the tiara pilot study. Neth Heart 2011;19:214-22

11. Zabalgoitia M, Halperin JL, Pearce LA, et al. Transesophagea echocardiographic correlates of clinical risk of echocardiographic correlates of clinical isk of prevention in atrial fibrillation III investigators. J Am Coll Cardid. prevention in atriat

12. Kamp O, Verhorst PM, Welling RC, Visser CA. Importance of left atrial appendage flow as a predictor of thromboembolic events in patients with atrial fibrillation. Eur Heart J. 1999;20:979-85.

3. Homma S, Sacco RL. Patent foramen ovale and stroke. Circulation. 2005;112:1063-72

14. Lamy C, Giannesini C, Zuber M, et al. Clinical and imaging findings in cryptogenic stroke patients with and without paten foramen ovale: The pfo-asa study. Atrial septal aneurysm. Stroke. 2002;33:706-11.

15. Mazzucco S, Li L, Binney $L$, et al. Prevalence of patent foramen ovale in cryptogenic transient ischaemic attack and non-disabling stroke at older ages: A population-based study, systematic review, and meta-analysis. Lancet Neurol. study, systematic

16. Kent $D M$, Ruthazer $R$, Weimar $C$, et al. An index to identify stroke-related vs incidental patent foramen ovale in cryptogenic stroke. Neurology. 2013;81:619-25.

7. Furlan AJ, Reisman M, Massaro J, et al. Closure or medical therapy for cryptogenic stroke with patent foramen ovale. N
Eng/ J Med. 2012:366:991-9.

8. Carroll JD, Saver $\mathrm{L}$, Thaler $D E$, et al. Closure of patent foramen ovale versus medical therapy after cryptogenic stroke. N Eng/ Med. 2013;368:1092-100.

19. Sondergaard L, Kasner SE, Rhodes JF, et al. Patent foramen ovale closure or antiplatelet therapy for cryptogenic stroke. N Eng/ J Med. 2017;377:1033-42.

20. Lee PH, Song JK, Kim JS, et al. Cryptogenic stroke and high-risk patent foramen ovale: The defense-pfo trial. J Am Coll Cardiol. 2018;71:2335-42

21. Sinha RS, Hussain Z, Bhatia N, Stoddard MF. Risk of recurrent neurologic stroke or transient ischemic attack in patients with cryptogenic stroke and intrapulmonary shunt. Echocardiography. 2016;33:276-80.

22. Abushora MY, Bhatia $\mathrm{N}$, Alnabki Z, et al. Intrapulmonary shunt is a potentially unrecognized cause of ischemic stroke and transient ischemic attack. J Am SOC Echocardiogr. 2013:26:683-90.

23. Ntaios $G$, Pearce LA, Meseguer E, et al. Aortic arch atherosclerosis in patients with embolic stroke of undetermine source: An exploratory analysis of the navigate esus trial. Strok 2019;50:3184-90

24. Kronzon I, Tunick PA. Aortic atherosclerotic disease and stroke. Circulation. 2006;114:63-75.

25. Harloff A, Simon J, Brendecke S, et al. Complex plaques in the proximal descending aorta: An underestimated embolic source of stroke. Stroke. 2010;41:1145-50.

26. Svedlund $S$, Wetterholm R, Volkmann R, Caidahl K. Retrograde blood flow in the aortic arch determined by transesophageal Doppler ultrasound. Cerebrovasc Dis. 2009;27:22-8.

27. Tunick PA, Rosenzweig BP, Katz ES, et al. High risk for vascular events in patients with protruding aortic atheromas: $A$ events in patients with protruding aortic atheromas. A

28. Amarenco $P$, Davis $S$, Jones EF, et al. Clopidogrel plus aspirin versus warfarin in patients with stroke and aortic arch plaques Stroke. 2014:45:1248-57.

29. Gupta A, Baradaran $H$, Schweitzer AD, et al. Carotid plaque MR and stroke risk: A systematic review and meta-analysis. Stroke. 2013:44:3071-7.

30. Mono ML, Karameshev A, Slotboom J, et al. Plaque characteristics of asymptomatic carotid stenosis and risk of stroke. Cerebrovasc Dis. 2012;34:343-50.

31. Kopczak A, Schindler A, Bayer-Karpinska A, et al. Complicated carotid artery plaques as a cause of cryptogenic stroke. J Am Coll Cardiol. 2020;76:2212-22.

32. Fakih R, Roa JA, Bathla G, et al. Detection and quantification of symptomatic atherosclerotic plaques with high-resolution imaging in cryptogenic stroke. Stroke. 2020;51:3623-31.

33. Brinjikji W, Huston J, 3rd, Rabinstein AA, et al. Contemporary carotid imaging: From degree of stenosis to plaque vulnerability. J Neurosurg. 2016;124:27-42.

34. Mark IT, Nasr DM, Huston J et al. Embolic stroke of undetermined source and carotid intraplaque hemorrhage on MRI : A systemic review and meta-analysis. Clin Neuroradiol. 2021;31:307-13.
35. Fu W, Crockett A, Low G, Patel V. Internal carotid artery web: Doppler ultrasound with CT angiography correlation.J Radiol Case Rep. 2015:9:1-6.

36. Antiguedad-Munoz J, de la Riva P, Arenaza Choperena G, et al. Internal carotid artery web as the cause of recurrent cryptogenic ischemic stroke. J Stroke Cerebrovasc Dis. 2018;27:e86-7.

37. Zhang AJ, Dhruv P, Choi P, et al. A systematic literature review of patients with carotid web and acute ischemic stroke. Stroke. 2018:49:2872-6.

38. Mac Grory B, Emmer BJ, Roosendaal SD, et al. Carotid web: An occult mechanism of embolic stroke. J Neurol Neurosurg Psychiatry. 2020;91:1283-9.

39. Mac Grory B, Cheng D, Doberstein C, et al. Ischemic stroke and internal carotid artery web. Stroke. 2019;50:e31-4.

40. Mac Grory B, Nossek E, Reznik ME, et al. Ipsilateral internal carotid artery web and acute ischemic stroke: A cohort study, systematic review and meta-analysis. PLoS One. 2021:16:e0257697.

41. Haynes J, Raz E, Tanweer O, et al. Endarterectomy for symptomatic internal carotid artery web. J Neurosurg. 2020;1-8.

42. Salehi Omran S, Hartman A, Zakai NA, Navi BB. Thrombophilia testing after ischemic stroke: Why, when, and what? Stroke. 2021; $52: 1874-84$

43. Chiasakul T, De Jesus E, Tong J, et al. Inherited thrombophilia and the risk of arterial ischemic stroke: A systematic review and meta-analysis. J Am Heart Assoc. 2019;8:e012877.

44. Kalaria $\mathrm{C}$, Kittner $\mathrm{S}$. The therapeutic value of laboratory testing for hypercoagulable states in secondary stroke prevention. Neurol Clin. 2015;33:501-13.

45. Navi BB, Sherman CP, Genova R, et al. Mechanisms of ischemic stroke in patients with cancer: A prospective study. Ann Neurol. 2021:90:159-69.

46. Neilson LE, Rogers LR, Sundararajan S. Evaluation and treatment of a patient with recurrent stroke in the setting of active malignancy. Stroke. 2019;50:e9-e11.

47. Rioux B, Touma L, Nehme A, et al. Frequency and predictors of occult cancer in ischemic stroke: A systematic review and meta-analysis. Int J Stroke. 2021;161:12-9.

48. Davies A, Van Leer L, Chan J, et al. Stroke in patients with cancer in the era of hyper-acute stroke intervention. Intern Med J. 2021. doi: 10.1111/imj.15353: Online ahead of print.

49. Panicucci E, Bruno C, Ferrari V, Suissa L. Recurrence of ischemic stroke on direct oral anticoagulant therapy in a patient with marantic endocarditis related to lung cancer. J Cardiol Cases. 2021;23:242-5

50. Yamaura G, Ito T, Miyaji Y, et al. Therapeutic efficacy of heparin and direct factor $X a$ inhibitors in cancer-associated cryptogenic ischemic stroke with venous thromboembolism. Thromb Res. 2021:206:99-103.

51. Barrett KM, Meschia JF. Genetic stroke syndromes. Continuum (Minneap Minn). 2014;20:399-411.

52. Lindgren A. Stroke genetics: A review and update. I Stroke. 2014;16:114-23. 